\title{
A NECESSIDADE DE REINVENTAR AS EMPRESAS
}

\author{
José Ernesto Lima Gonçalves \\ Professor do Departamento de Administração Geral e \\ Recursos Humanos da EAESP/FGV e Consultor.
}

RESUMO: Para algumas empresas a adaptação aos novos tempos é inevitável, uma questão de vida e morte. Para outras; a adaptação é uma recomendação, uma medida preliminar de segurança. As empresas contemporâneas estão precisando mudar em função de pressões externas e internas inéditas tanto na variedade como na intensidade e alguns eventos estão sinalizando a chegada da nova empresa. Elas carregam dentro de si as sementes da sua própria destruição. Seus empregados hoje são mais educados e reivindicadores do que nunca, muitas decisões estão dispersas no meio de um corpo enorme e diversificado de especialistas e gerentes, as forças políticas internas estão mais intensas e competem com a própria empresa pela energia vital de seus empregados. A tecnologia relacionada com a gestão das empresas está provocando mudanças até mais intensas que as causadas pela tecnologia de processo de fabricação no final do século passado. Novas premissas, adequadas a novos fatores, devem orientar o projeto das empresas destinadas a sobreviver e prosperar nos novos tempos.

ABSTRACT: To some companies, adapting to new times is inevitable, a life or death decision. To others, adaptation is recommended as a precaution. Contemporary companies have to change because of external and internal pressures that are novel both in intensity and variety and we have seen signs of the arrival of the new enterprise. They carry the seeds of their destruction inside themselves. Their employees are more educated and demanding than ever, many decisions are dispersed in a huge and diversified body of specialists and managers, the internal political powers are intense and compete with the company itself for the vital energy of employees. Management related technologies are leading to even deeper changes than those caused by process technologies in the end of the last century. New premises, more adequate to these new factors, shall guide the design of companies that are to survive and row in these new times.

PALAVRAS-CHAVE: transformação organizacional, tecnologia, desenho organizacional, estratégia empresarial.

KEY WORDS: business transformation, technology, organizational design, business strategy. 
Para algumas empresas a adaptação aos novos tempos é inevitável, uma questão de vida ou morte. Para outras, a adaptação é uma recomendação, uma medida preliminar de segurança. Na verdade, as empresas têm pelo menos três motivos para se adaptarem: tirar o atraso das décadas que passaram sem realizar maiores ajustes, adequar-se às novas exigências que obrigam as empresas a aprenderem a se modificar continuamente, e simplesmente corrigir o que se provou não estar certo no desenho das empresas convencionais.

Muitas das idéias sobre a necessidade de se reinventar as empresas são encontradas nas páginas introdutórias dos livros atuais sobre transformação organizacional, estratégia empresarial e administração moderna. São argumentos de todos os tipos e graus de relevância, mas o seu número e variedade sugerem que a sobrevivência das empresas passa por caminhos muito diferentes daqueles utilizados até agora.

Para entender por que um redesenho radical e profundo deve ser feito nas empresas, devemos entender como o contexto global no qual essas empresas operam mudou.' Alguns eventos estão sinalizando a chegada da nova empresa: o fim do emprego como conhecemos ao longo deste século, a tecnologia que elimina as distâncias e o tempo, o crescente nível de exigência dos consumidores, o surgimento de novos tipos de concorrência, tanto em nível doméstico, como internacional.

A implementação do ponto de vista do cliente na gestão das empresas praticamente exige que se faça o redesenho de seus processos de negócios. A adoção de uma estrutura baseada nos processos significa, em geral, dar menos ênfase à estrutura funcional do negócio ${ }^{2}$ e o emprego de outros modelos organizacionais e de negócios.

As empresas contemporâneas não estão apenas vivendo num ambiente que apresenta novos desafios: elas carregam dentro de si as sementes da sua própria destruição. Seus empregados hoje são mais educados e reivindicadores do que nunca, muitas decisões estão dispersas no meio de um corpo enorme e diversificado de especialistas e gerentes, as forças políticas internas são intensas e competem com a própria empresa pela energia vital de seus empregados.
O final da "era de ouro" na década de 70 trouxe a busca do "segredo" dos japoneses, a preocupação com a qualidade, as tentativas desesperadas (do estilo downsizing) e as recomendações radicais, como a reengenharia. Era preciso descobrir o que fazer para que as empresas americanas (e aquelas que, como muitas das nossas, haviam sido criadas e dirigidas segundo o modelo americano) pudessem voltar a competir. Parecia que o mundo todo operava de modo inadequado para as empresas que seguiam o modelo americano. $\mathrm{Na}$ verdade, as empresas européias também passaram por maus bocados nesse período.

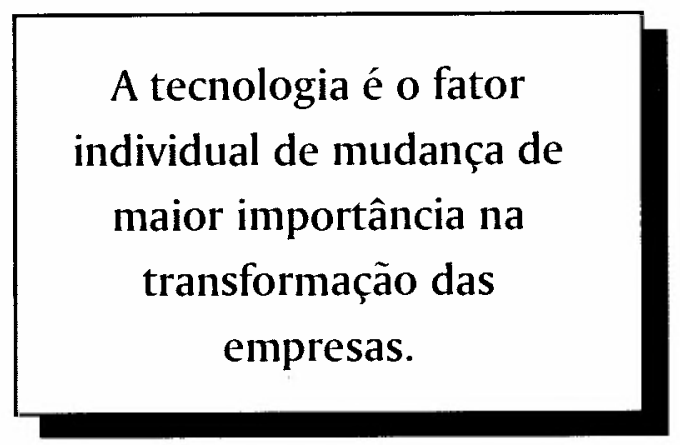

Não bastasse esse incrível elenco de forças que estão levando as empresas a mudar, muitas delas estão vivendo o período pósreengenharia, depois de passarem, devidamente ou não, por profundas e radicais transformações. As chances são de que essas mudanças tenham sido feitas de maneira atabalhoada e ineficaz, de modo que o desafio para essas empresas é multiplicado.

É fundamental reconhecermos a influência da maneira americana de administrar as empresas e o seu impacto nas empresas instaladas no Brasil. Fomos treinados no modelo americano e criamos toda uma coleção de empresas que, para o bem ou para o mal, pensam e agem como seus paradigmas americanos. Assim, entender o que está acontecendo com as empresas americanas pode contribuir muito para o aperfeiçoamento da gestão das empresas instaladas no Brasil. Pode também ajudar a compreender o que não deu certo aqui exatamente porque não estamos nos Estados Unidos.

O resultado mais visível dessas mudanças é o declínio de empresas estabelecidas há muito tempo, ${ }^{3}$ que mostraram bons resultados em outras épocas. Os Quadros 1 e 2
1. MITROFF, Ian, LINSTONE, Harold. The unbounded mind. London: Oxford, 1993.

2. DAVENPORT, Thomas. Reengenharia de processos. Rio de Janeiro: Campus, 1994

3. MORRIS, Daniel, BRANDON, Joel Reengenharia: reestruturando a sua empresa. São Paulo: Makron, 1994. 


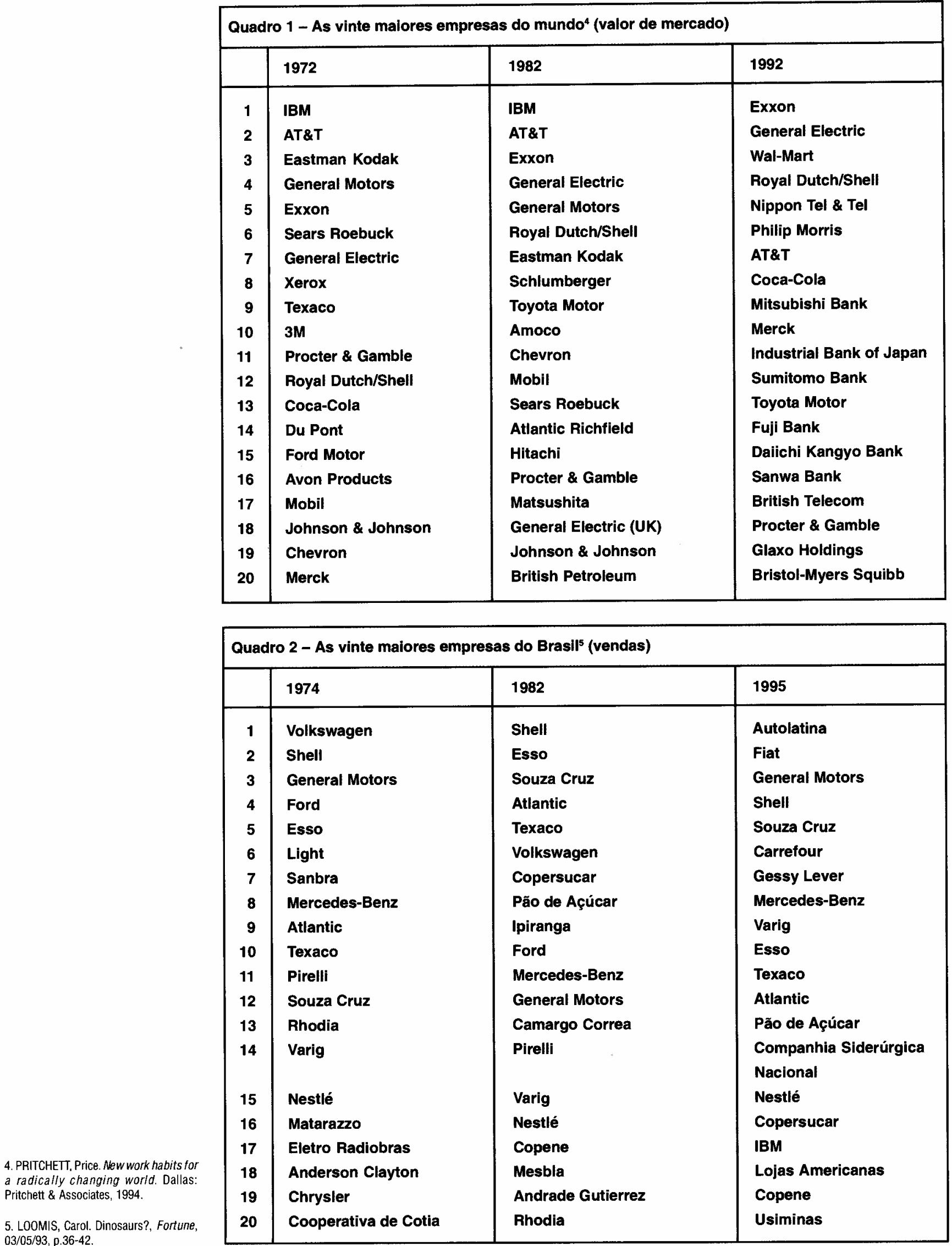


mostram como o elenco das vinte maiores empresas tanto no Brasil como no mundo tem mudado de maneira significativa. Algumas empresas tradicionais simplesmente desapareceram do ranking em menos de dez anos; enquanto outras, sem tradição entre as maiores, despontaram como líderes de suas respectivas indústrias.

\section{O CAMINHO ATÉ AQUI}

Em 1985 já se falava em reinventar a empresa. ${ }^{6}$ Naquela época já eram percebidas as tendências que exigiam que as organizações se reinventassem: o surgimento da sociedade da informação, o redirecionamento estratégico dos recursos de capital para os recursos humanos, a eliminação de níveis intermediários de gerência e a previsível falta de capacidade produtiva das empresas para atender ao crescimento dos mercados nas décadas de 80 e 90 .

Modelos antigos, que tanto sucesso fizeram em décadas passadas já não se mostram mais adequados. Pior, empresas que foram modelo de suas respectivas indústrias simplesmente desapareceram, deixando evidente que não conseguiram se adaptar da forma $\mathrm{e}$ na velocidade requeridas. É o caso da Pan American, que, depois de inventar o transporte aéreo de passageiros, dominou a tecnologia e a indústria durante mais de cinqüenta anos, tornando-se o grande modelo de empresa aérea. Depois de quase setenta anos de sucesso empresarial, a Pan American faliu ao final de um doloroso conjunto de tentativas de ajuste às novas condições. Mesmo empresas que não chegaram a fechar têm apresentado problemas que também indicam que seus modelos de gestão, sua organização e seus recursos não são mais adequados. A IBM e a GM, por exemplo, apresentaram recentemente os maiores prejuízos da história das corporações.

Até a década de 60 os EUA viveram uma notável hegemonia industrial, comercial e econômica que vinha desde o pós-guerra. Os chamados golden years da indústria americana levaram a empresas que não se preocupavam com custos, pois tudo era vendido, não precisavam de grande investimentos em qualidade, pois a demanda estava sempre insatisfeita, não precisavam se preocupar com custos, pois o preço não era pro- blema e não havia concorrência que preocupasse. Com isso, as empresas foram se tornando complacentes ${ }^{8}$ comprometendo-se com essas idéias que nunca antes tinham sido parte de sua concepção e nem se sustentariam numa situação um pouco mais adversa. A contrapartida da complacência das empresas é a filosofia do "direito adquirido", "que leva as pessoas a pensarem que não precisam ganhar o que recebem, que recebem pelo que são e não pelo que produzem.

Durante esse período, os EUA e Inglaterra criaram toda uma geração de gerentes de denominador. ${ }^{10}$ No período de 1975 a 1985 assistimos ao desaparecimento de empresas que haviam tido papel histórico nos seus setores e na história do desenvolvimento ocidental. A Pan American, nos Estados Unidos, e as empresas Matarazzo, no Brasil, são exemplos notáveis. Quando as empresas perceberam que a situação havia mudado, a partir de 1980, assistimos à procura desesperada do "segredo" japonês pelas empresas americanas, com o estudo das artes gerenciais japonesas, a ascensão do JIT ${ }^{11}$ e dos movimentos de qualidade etc. Afinal, se os japoneses estavam conseguindo tantos resultados em tão pouco tempo, devia haver alguma coisa que pudesse ser copiada pelos americanos e que lhes devolvesse a capacidade de competir. Os americanos simplesmente se esqueceram de que eles não haviam competido com ninguém desde antes da Segunda Guerra Mundial.

Todos esses esforços não foram suficientes e no início da década de 90 as empresas começaram a tomar as últimas e mais radicais medidas: downsizing, reestruturação e reengenharia. Quando Hammer ${ }^{12}$ diz que a reengenharia não procura consertar nada, mas corresponde à reinvenção da forma de funcionar da empresa, ele está colocando por escrito as idéias que muitos dirigentes já estavam murmurando.

Muitas das empresas brasileiras foram montadas a partir da década de 40 , projetadas e administradas por pessoal estrangeiro ou nacional que aprendeu administração de acordo com os princípios da "verdade". Aliás, todas as pessoas que fizeram qualquer curso de Engenharia, Administração ou Economia nesse período estiveram aprendendo as "verdades" do período de fartura americana do pós-guerra. Embora nunca tenhamos vivido no Brasil esse ambiente da economia
6. NAISBITT, John, ABURDENE, Patricia. Re-inventing the corporation. New York Warner, 1985.

7. KANTER, Rosabeth Moss. World class New York: Simon \& Schuster, 1995.

8. BARDWICK, Judith. Danger in the comfort zone. New York: Amacon, 1995

9. A palavra inglesa "entitlement", utilizada por Judith Bardwick, foi traduzida por nós pela expressão "direito adquirido".

10. Referência ao fato de a estratégia básica para recuperar os níveis de resultados se basear na redução dos custos e não no aumento de receitas, cf. HAMEL, Gary, PRAHALAD, C. K. Competing for the future. Boston, MA: Harvard Business School Press, 1994

11. Sigla correspondente a "just-in-time".

12. HAMMER, Michael. Reengineering the corporation. New York: HarperBusiness, 1994. 
americana do pós-guerra, as nossas empresas importaram diretamente os ensinamentos que estavam sendo desenvolvidos e passaram a apresentar exatamente as mesmas características de suas contrapartes americanas: o superdimensionamento da burocracia, o excesso de controles e a pobreza de resultados, além, é claro, da pequeníssima capacidade de competir.

Para as empresas brasileiras a onda da concorrência também chegou mais tarde. Ao contrário das americanas, que passaram a ter crescentes dificuldades já na década de 70 , as brasileiras foram poupadas até o final da década de 80 , graças a mecanismos de proteção dos mercados nacionais. Com isso, estamos uma ou duas décadas atrás dos americanos na busca dos mecanismos adequados de reformulação dos negócios.

\section{UM POUCO DE HISTÓRIA RECENTE}

Às vésperas da Segunda Guerra Mundial havia pelo menos três grandes pólos de desenvolvimento político e econômico no mundo: a Europa, com destaque para a Alemanha e para a Inglaterra, o Japão, em sua posição de potência alternativa na região do Pacífico, disputando com os Estados Unidos a hegemonia na região, e os Estados Unidos.

Ao final da Segunda Guerra Mundial, a Europa havia sido devastada pela guerra. A Alemanha havia sido sistematicamente destruída e não representava mais nada em termos econômicos. O Japão também tinha sido arrasado e nada de valor econômico tinha escapado à destruição. Os demais países na área do conflito, o que quer dizer a Europa, da Inglaterra à Rússia, da Suécia à Palestina, o norte da África, a China e seus vizinhos estavam todos destruídos e necessitando de tudo: alimentos, medicamentos, máquinas para a reconstrução, infra-estrutura, transporte, energia, alojamento etc.

Dos três grandes pólos econômicos e industriais apenas o americano havia sobrevivido à destruição ${ }^{13} \mathrm{e}$, mais que isso, estava inteiro, preparado e experiente com a logística da guerra para exercer o papel de exportador para o mundo. Os outros países tiveram que reconstruir sua indústria, sua infraestrutura, seu mercado a partir do zero e, é claro, aproveitaram para aplicar os poucos recursos disponíveis nos pontos prioritários e da maneira mais eficiente possível. ${ }^{14} \hat{E}$ a época dos automóveis estilo Prefect e Trabant na Europa, da década de reconstrução no Japão, em que toda a população ativa japonesa trabalhou seis dias por semana sem direito a férias e doou a remuneração de suas férias e descanso para o fundo de reconstrução nacional. Ao longo desses processos, forjou-se uma população forte, que valorizava o esforço e a conquista de cada palmo, de cada emprego conquistado. Surgiram desse processo fábricas mais racionais, processos mais "enxutos"15 e produtos mais essenciais. Esses fatores viriam a fazer diferença a partir do início da década de 70 .

De repente, no início da década de 70 , as economias desses países começaram a dar sinais de vida. Os países passaram a ser autônomos com relação a diversos produtos que antes importavam dos Estados Unidos e, muito pior, mostravam que estavam prontos - para passar a competir com os produtos americanos no mercado mundial e no próprio mercado americano. Os anos de ouro da economia americana tinham chegado ao fim, mas os americanos demoraram a acreditar nisso.

Durante os anos de afluência, as empresas se davam tão bem que podiam se dar ao luxo de empregar um contingente de pessoas não produtivas. ${ }^{16} \mathrm{De}$ repente, estavam tendo que perder de uma só vez toda a folga embutida nos seus sistemas produtivos ao longo de décadas de uma filosofia de gestão baseada na fartura de recursos, na inexistência de concorrência internacional e em nenhuma preocupação com os custos.

$A$ intensidade e a abrangência das mudanças por que passam as empresas pode ser melhor avaliada quando olhamos os negócios que surgiram e desapareceram nas últimas décadas. $\mathrm{O}$ Quadro 3 ilustra este ponto ao apresentar exemplos de negócios que eram considerados sólidos e tradicionais e que desapareceram recentemente ou estão desaparecendo. Da mesma forma, negócios inimagináveis há pouco tempo estão presentes no mundo atual, oferecendo novas oportunidades e exemplos de iniciativa para as nossas empresas.

Em particular, deve-se destacar o crescimento do tamanho e da importância do setor de serviços, no qual estão surgindo praticamente todas as grandes oportunidades de negócios das últimas décadas. Pelo menos dez das vinte maiores empresas do 


\begin{tabular}{|l|l|l|}
\hline \multicolumn{2}{|l|}{ Quadro 3 - Negócios que surglram e desapareceram nas últimas décadas } \\
\hline NEGÓcIOS DESAPARECIDOS & NOVOS NEGóciOS & NEGÓcIOS TERMINAIS \\
\hline $\begin{array}{l}\text { Transporte marítimo de } \\
\text { passageiros }\end{array}$ & $\begin{array}{l}\text { Provedores de serviços na } \\
\text { Internet }\end{array}$ & $\begin{array}{l}\text { Fabricação de máquinas de } \\
\text { escrever }\end{array}$ \\
\hline Fabricação de pianos & Fabricação de CDs & Discos de vinil \\
\hline $\begin{array}{l}\text { Serviços gráficos com } \\
\text { linotipo }\end{array}$ & Produção de software & $\begin{array}{l}\text { Carburadores e } \\
\text { distribuidores }\end{array}$ \\
\hline $\begin{array}{l}\text { Fabricação e reparo de } \\
\text { rádios a válvula }\end{array}$ & $\begin{array}{l}\text { Produção de conteúdo para } \\
\text { canais de comunicação }\end{array}$ & Aluguel de fitas VHS \\
\hline Aluguel de filmes $16 \mathrm{~mm}$ & Serviços de pager & $\begin{array}{l}\text { Publicação de jornais } \\
\text { diários }\end{array}$ \\
\hline
\end{tabular}

mundo atuam principalmente no setor de serviços, conforme pode ser observado no Quadro 1.

Durante muitos anos, o verdadeiro e permanente valor estratégico era o ser grande, de modo que o crescimento era o único caminho realmente válido. Se, de repente, ser grande não é o melhor e crescer não é sempre adequado para todas as empresas, é importante repensar e reavaliar. As economias alemã e italiana são baseadas em empresas pequenas e médias que dominam micronichos globais e que são robustas e poderosas, embora nunca venham a ser candidatas à lista "Fortune 500". ${ }^{17}$

Algumas experiências recentes mostram que é perfeitamente possível enfrentar e superar as dificuldades decorrentes dessas novas forças do mercado. O sucesso de novas empresas aéreas como a TAM, a United e a Singapore Airlines ante empresas tradicionais como a Varig, a Eastern e a Air France é eloqüente. Mesmo em setores tradicionais como o das seguradoras e dos bancos temos visto resultados interessantíssimos decorrentes de profundas revisões dos métodos operacionais postas em prática.

\section{GENTE TAMBÉM É IMPORTANTE}

Estamos entrando numa nova fase da história, na qual cada vez menos empregados serão necessários para produzir os bens e serviços necessários ${ }^{18}$ para a população global. As empresas estão substituindo seus empregados full-time por empregados em tempo parcial. ${ }^{19}$ Apenas $55 \%$ dos trabalhadores ingleses têm empregos em tempo integral e percebe-se que a economia tem uma boa dose de capacidade ociosa, mas no âmbito dos indivíduos e não das organizações. A eliminação de cargos de trabalho provocada pela reorganização do trabalho, em projetos de reengenharia, downsizing e outros, deve continuar pelo "futuro previsível". ${ }^{20}$

Mais do que isso, as empresas ficarão com poucos empregados, de modo que procurarão os melhores, competindo entre si pelos seus recursos mais essenciais: pessoal qualificado, com as características indispensáveis para o sucesso nos novos tempos.

As mudanças nas características da força de trabalho também levam as empresas a reagir, embora nem sempre isso ocorra. Um estudo realizado por um banco norteamericano revela que dois a três empregados em cada cinco têm tido problemas em conciliar suas demandas familiares com as profissionais. No entanto, as empresas são projetadas com base na premissa de que seus empregados podem dedicar toda a sua energia e tempo à empresa. ${ }^{21}$

As idéias mais conhecidas estão sendo questionadas, como, por exemplo, as "tradições japonesas" de empregos vitalícios, fidelidade à empresa, salários sempre crescen-
17. PETERS, Tom. Rompendo as barreiras da administração. Rio de Janeiro: Harbra, 1993.

18. RIFKIN, Jeremy. 0 fim dos empregos: o declínio inevitável dos niveis dos empregos e a redução da força global de trabalho.São Paulo: Makron Books, 1996.

19. HANDY, Charles. The age of paradox Boston, MA: Harvard Business School Press, 1994.

20. The Wall Street Journal, citado em RIFKIN, Jeremy. Op. cit.

21. BAILYN, Lotte. Changing the conditions of work: responding to increasing work force diversity and new family patterns. In: KOCHAM, Thomas et al. Transforming organizations, London: Oxford, 1992. 
22. Entrevistas do autor com professores universitários japoneses em Tóquio e Osaka, em 1982 e 1985

23. Chama-se de baby boom o periodo de 1946 a 1960 , em que nasceram 76 milhōes de americanos, numa taxa de crescimento populacional sem paralelo na história do país.

24. BARDWICK, Judith. Op. cit.

25. MILLS, D. Quinn. Orenascimento da empresa. Rio de Janeiro: Campus, 1993.

26. Utilizamos a palavra "indústria" para nos referirmos ao conjunto das empresas que atuam num determinado setor da atividade econômica. Não deve ser confundida com a conotação de empresa industrial.

\section{Business Week, 19/06/95, p.36.}

28. FREEDMAN, David. Is management still a science?, Boston, MA: Harvard Business Review, Nov./Dec. 1992, p.2638.

29. DAVENPORT, Thomas. Op. cit. tes (ainda que marginalmente), que são idéias que tiveram origem no mesmo conjunto de motivos e na mesma época que os mecanismos de proteção aos empregos desenvolvidos nas sociedades européias: o período de reconstrução depois da Segunda Guerra Mundial.

Algumas práticas operacionais novas estão trazendo desafios inéditos e preocupações para as quais ainda não existem respostas maduras. É o caso das empresas que estão dando maior poder de decisão ao seu pessoal de campo e ligando-os à empresa por meio eletrônico, como a Otis Elevators e muitas empresas de vendas. Com todas essas variáveis flutuando e as transformações ocorrendo, as pessoas estão desorientadas, desde o principal executivo até o operador dos equipamentos industriais.

A sociedade japonesa também se preocupa com a demasiada facilidade da vida das novas gerações de japoneses. Desde o início da década de 80 , diversos setores da sociedade japonesa ${ }^{22}$ discutem como desenvolver nos jovens japoneses os valores da competição pela sobrevivência, da poupança, da previdência etc. Consideram que as novas gerações não têm precisado fazer nenhum esforço notável, receberam tudo de graça e não dão valor às conquistas e resultados.

Além do desafio representado pelo renascimento dos seus concorrentes na Europa e no Oriente, nas décadas de 70 e 80 , as empresas americanas tinham que enfrentar a necessidade de empregar o enorme contingente de pessoal nascido nos anos do baby boom. ${ }^{23}$ Ao contrário, os golden years tinham sido uma excelente oportunidade para os nascidos nas décadas de 20 e 30 , que tiveram enorme facilidade de emprego. ${ }^{24}$

Existe uma pressão dos próprios empregados por maior participação nas decisões referentes ao trabalho deles..$^{25}$ Por outro lado, está crescendo a importância do empregado individual perante a empresa, de modo que o alinhamento entre as expectativas das pessoas e as das empresas nunca teve tão grande importância. E, devemos concordar, as técnicas de mudança organizacional empregadas ultimamente não contribuem muito para a preservação do equilíbrio entre esses conjuntos de expectativas.

As indústrias-núcleo ${ }^{26}$ da nova economia (entretenimento, educação, serviços de informática, comunicações e consultoria) estão criando de 120.000 a 460.000 novos empregos por ano nos EUA cada uma, enquanto o governo, a manufatura, a construção civil e os serviços financeiros estão perdendo de 30.000 a 100.000 empregos por ano cada uma. ${ }^{27}$

\section{NOVAS PREMISSAS PARA A ADMINISTRAÇÃO}

Os anos 90 serão conhecidos no futuro como o período da grande transição da forma pela qual as empresas são estruturadas e conduzidas. A tradicional abordagem científica à administração pretendia prover os administradores com a capacidade de analisar, predizer e controlar o comportamento das organizações complexas pelas quais eles eram responsáveis. Mas o mundo que a maioria desses administradores habita frequientemente parece ser imprevisível, incerto e mesmo incontrolável. ${ }^{28}$

Temos, por exemplo, o caso da Internet, que durante vinte anos foi apenas uma forma eficiente e barata de comunicação a longa distância entre cientistas e maníacos por informática. De repente, tornou-se um poderosíssimo veículo de comercialização, um eficaz instrumento de gestão de empresas dispersas pelo mundo e uma fenomenal alavanca da utilização de comunicação e informática nas empresas do mundo, a maioria das quais não está preparada para operar nesse novo ambiente.

Os golden years duraram 25 anos tempo suficiente para que duas ou três gerações de administradores passem pelas empresas, para que as idéias tornem-se verdades e os novos administradores passem a ser formados (dentro e fora das empresas) de acordo com essas novas verdades. As práticas de administração de empresas e de gestão de negócios dos golden years, da definição de estratégias até o desenho dos mecanismos operacionais de gestão dos recursos, dos critérios para dimensionamento de recursos até o raciocínio da definição de preços de produtos, acabaram se tornando as bases da formação técnica e acadêmica de gerações de administradores de empresas. $\mathrm{O}$ fato de terem as empresas japonesas descoberto (ou pelo menos implementado), por exemplo, a administração por processos muito antes do Ocidente ajuda a explicar o seu sucesso econômico mundial. ${ }^{29}$ 
Os tempos novos exigem idéias inovadoras e eficazes, no entanto, a maioria dos administradores continua a repetir o mesmo padrão, pensando que seus êxitos passados vão criar o futuro. ${ }^{30}$ Não que seus gerentes não enxerguem a necessidade de mudar: muitas vezes eles não entendem que os mecanismos que estão utilizando para mudar não promovem a mudança necessária.

As novas estratégias de gestão propõem a criação do futuro da empresa,${ }^{31}$ com base no raciocínio de que uma empresa só pode controlar seu destino se compreender como controlar o destino de sua indústria.

Na sociedade do conhecimento, os administradores devem se preparar para abandonar tudo o que sabem. ${ }^{32}$ Todas as organizações precisam estar preparadas para abandonar tudo o que fazem e, mais, devem se dedicar a criar o novo. Na verdade, os administradores precisam recorrer a três atividades sistemáticas: o aperfeiçoamento contínuo do que fazem, a exploração do seu conhecimento e o aprendizado de como inovar. No entanto, as empresas passaram muito tempo se acostumando a olhar mais para dentro de seus próprios limites que para fora e para frente. ${ }^{33}$

O que se observa é que as mudanças organizacionais geralmente são reativas quando deveriam ser resultado de previsão. ${ }^{34} \mathrm{~A}$ empresa orientada para o cliente e que deseja criar uma boa impressão nos seus "momentos da verdade" deve ser organizada para a mudança. ${ }^{35}$ Por exemplo, deve achatar a pirâmide, eliminar níveis hierárquicos de responsabilidade para conseguir responder direta e rapidamente às demandas dos seus clientes. $^{36}$

Como tudo o que eles achavam que sabiam e conheciam está sendo duramente questionado, os executivos principais das empresas estão passando a duvidar de sua competência para manter suas empresas no século XXI. ${ }^{37} \mathrm{Um}$ exemplo claro de idéia que não funciona mais é o tamanho da empresa. Há algum tempo, o tamanho da empresa era um asset estratégico e uma barreira contra a entrada de novos concorrentes. De uns tempos para cá, o tamanho da empresa pode ser uma desvantagem, pois as grandes empresas estão passando por dificuldades por causa de seu gigantismo ou estão procurando maneiras de evitar maio- res problemas por causa de seu tamanho. Seus novos concorrentes parecem competir com um jogo diferente de regras, desconhecidas até há pouco. $\mathrm{Na}$ Alemanha, uma pequena empresa está desafiando a gigante estatal do setor de telecomunicações, a Telekom, ao vender a versão em CDROM das listas telefônicas por 39 dólares, enquanto a empresa estatal vende a sua versão por mil dólares. ${ }^{38}$

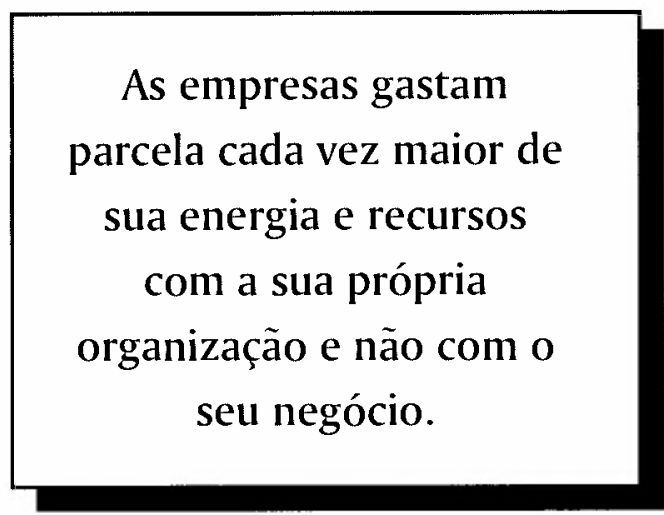

Apenas o tamanho não garante nada e a boa reputação também não assegura sucesso continuado. Ironicamente, as reais dimensões da transformação organizacional a ser enfrentada por muitas empresas foram estabelecidas por novatos, que mudaram as regras do jogo, e não pelos que já participavam do jogo. ${ }^{39} \mathrm{~A}$ pequena Netscape assusta a Microsoft, que mesmo quando era pequena já assustava e acabou por derrotar concorrentes muito maiores que ela própria.

Algumas empresas já perceberam que para terem lugar no futuro terão que aprender a aprender, o que exige que sejam criados mecanismos adequados, alguns por meio de estruturas específicas (times), outros por meio de alinhamento estratégico (para reforçar culturas), outros ainda por meio de esforços específicos (linhas de produção tipo laboratório). ${ }^{40}$

Os sistemas de aprendizado de uma empresa precisam ser tão complexos quanto o ambiente externo no qual ela opera. ${ }^{41} \mathrm{O}$ horizonte dos negócios está mudando rapidamente e se tornando mais complexo. As fronteiras estão se tornando mais porosas, quer entre as empresas na cadeia de suprimento, quer entre os concorrentes. As velhas distinções entre manufatura e serviços estão perdendo cada vez mais o significado.
30. LAND, George, JARMAN, Beth. Ponto de ruptura e transformação. São Paulo: Cultrix, 1990

31. Ver ACKOFF, Russel L. Redesigning the future. New York: Wiley, 1973; HAMEL, Gary, PRAHALAD, C. K. Op. cit.

32. DRUCKER, Peter. The new society of organizations, Boston, MA: Harvard Business Review, Sep./Oct. 1992, p.95104

33. HAMEL, Gary, PRAHALAD, C. K. Op cit.

34. McFEELY, Wilbur. Organization change. The Conference Board, 1972.

35. CARLZON, Jan. Moments of truth. New York: HarperCollins, 1987

36. Idem, ibidem.

37. NOLAN, Richard, CROSON, David Creative destruction. Boston, MA Harvard Business School Press, 1995.

38. Business Week, 19/02/96, p.21

39. HAMEL, Gary, PRAHALAD, C. K. Op. cit.

40. CLARKE, Thomas, MONKHOUSE Elaine. Repensando a empresa. São Paulo Pioneira, 1995.

41. Mark Goyder parafraseando Ashby em CLARKE, Thomas e MONKHOUSE, Elaine. Idem, ibidem. 


\section{A NOVA ORGANIZAÇÃO}

Cada vez mais as empresas gastam parcela crescente de sua energia e recursos com a sua própria organização e não com o seu negócio. ${ }^{42}$ As hierarquias tendem a aumentar de tamanho. A característica mais óbvia da evolução das hierarquias é a criação de camadas administrativas adicionais para acomodar o crescimento organizacional. ${ }^{43}$

Alguns estudos indicam que muitas empresas poderiam reduzir (downsize) sua força de trabalho pela metade sem nenhum prejuízo para o seu resultado operacional. ${ }^{44}$ Boa parcela dessa folga apareceu durante as décadas de implementação dos computadores e nunca foi adequadamente transformada em benefícios econômicos por causa de redução inadequada do quadro de pessoal das empresas.

Existem também as empresas que estão abandonando apêndices que adquiriram e aprenderam que, se pretendem sobreviver, devem retornar à gestão dos seus negócios básicos, dentro de um ambiente em mudança. Elas tentam reverter movimentos de diversificação que não foram bem planejados na década de $80 .^{45}$

O modelo que nos serviu durante séculos dá sinais de colapso. Há falhas no planejamento e no orçamento que não se consegue superar. Os resultados são irregulares, aparentemente aleatórios. Surgem prejuízos inesperados. A resposta - ineficiente - da organização é o aumento dos controles e o reforço da estrutura com a criação de novas áreas. O clima é ruim e os empregados estão frustrados e insatisfeitos. ${ }^{46} \mathrm{~A}$ transformação é inevitável e indispensável para a empresa que aspira chegar ao futuro em primeiro lugar. ${ }^{47}$

Durante quase meio século viveııus a ditadura dos princípios da administração de empresas. Durante esse período, as empresas foram projetadas, administradas e mantidas de acordo com os princípios da administração que foram inventados nas primeiras décadas do século XX. Essa rigidez conceitual estava prejudicando tanto as empresas que um autor contemporâneo criou (ou adotou) o termo "destruição criativa" para o processo pelo qual os princípios administrativos antigos em vigor nas organizações são substituídos por princípios novos, mais adequados à economia da informação. ${ }^{48}$
Algumas empresas estão se reestruturando com o objetivo de se tornarem mais empreendedoras: elas querem ficar mais próximas do cliente, querem que as decisões sejam tomadas pelas pessoas que têm acesso à informação e querem ser capazes de se mexerem mais depressa. ${ }^{49}$ Temos visto isso acontecer nas empresas prestadoras de serviços, na área comercial de várias empresas industriais e até mesmo em algumas empresas industriais que foram projetadas mais recentemente. Aparentemente apenas as unidades pequenas e os times são ágeis e adaptáveis o suficiente para prosperarem no mundo de mudanças de alta velocidade.

A organização moderna está rapidamente sendo transformada de uma estrutura feita de jobs num grande conjunto de trabalhos a serem realizados. ${ }^{50}$ Quando a economia estava mudando muito mais lentamente, as discrepâncias entre a matriz de cargos e o conjunto de trabalhos podiam passar despercebidas. Se uma novidade tecnológica, um novo mercado ou uma exigência legal abria uma nova área no conjunto de trabalhos, novos cargos podiam ser criados para cobrir o novo trabalho a ser feito. Isso levava a um aumento do número e da variedade de cargos, o que provocava o enrijecimento da estrutura pela especialização e não a flexibilização dos recursos. $\mathrm{Na}$ nova economia essa solução é absolutamente inaceitável, exigindo saídas mais criativas e inovadoras.

Uma vez que o conhecimento não favorece o desenvolvimento de hierarquias, na organização voltada ao conhecimento, a distinção entre as pessoas que trabalham com o conhecimento não pode ser baseada nesse ativo fundamental. ${ }^{51} \mathrm{~A}$ hierarquia, o princípio cultural pelo qual os negócios foram conduzidos e as empresas administradas por todo o último século, não mais parece prática ou relevante. Por outro lado, pessoas com conhecimentos diferentes formam times interdisciplinares para enfrentar desafios inéditos.

Os cargos estão sendo redefinidos e redesenhados. É o caso de empresas que estão utilizando times multifuncionais na área de projeto do produto (Refinações de Milho Brasil e Kodak americana), incentivando a integração do seu pessoal através da eliminação da circulação de papel e da adoção de 
sistemas informatizados integrados. Esperase que os empregados se comportem de modo novo e diferente, de uma maneira para a qual eles talvez não estejam preparados, nem para a qual tenham as habilidades necessárias.

Dirigentes e pensadores estão empenhados em descobrir as regras pelas quais as empresas terão que se organizar daqui para frente..$^{52} \mathrm{~A}$ maioria das estruturas organizacionais e práticas gerenciais foi criada para funcionar bem num mundo mais estável e previsível do que o que temos, adequadas para um ritmo de mudança muito mais modesto do que passou a vigorar. ${ }^{53}$

$\mathrm{O}$ aumento da produtividade dos trabalhadores do conhecimento (knowledge workers) e em serviços irá exigir mudanças fundamentais na estrutura das organizações. Ele poderá exigir até organizações totalmente novas. ${ }^{54}$ Às vezes poderá ser necessário criar novas formas estruturais, como as network organizations, que permitem que uma empresa seja grande quando for vantajoso ser grande e pequena quando for conveniente ser pequena. ${ }^{55}$

Identificada essa necessidade de transformação radical por que as empresas precisam passar, surgiu a idéia da reengenharia e estabeleceu-se um princípio radical: o projeto do trabalho não deve ser baseado na administração hierárquica e na especialização, mas nos processos de negócio e na criação de valor para os clientes. ${ }^{56}$ Essa nova maneira de enxergar a organização leva não apenas a desenhos organizacionais novos, mas também a novos mecanismos produtivos e gerenciais, com os quais as empresas precisarão se familiarizar.

\section{TECNOLOGIA E O REDESENHO DA EMPRESA}

A tecnologia é o fator individual de mudança de maior importância na transformação das empresas. ${ }^{57}$ No entanto, como já foi identificado há tempos, a simples substituição da grande máquina a vapor pelo grande motor elétrico na virada do século XIX para o XX não trouxe a melhoria de rendimento que as empresas industriais esperavam. Foi só quando as fábricas foram reprojetadas para tirarem proveito dos motores elétricos pequenos que os ganhos substanciais apareceram. $^{58}$
As empresas americanas investiram mais de um trilhão de dólares em tecnologia de informação e informática na década de 80 e só nos últimos anos viram a produtividade das áreas não-fabris melhorar. As novidades tecnológicas eram adaptadas a estruturas organizacionais e processos tradicionais, de modo que não era possível obter desempenho eficaz e explorar plenamente as possibilidades da novidade tecnológica. Recentemente, no entanto, as empresas começaram a reestruturar o workplace ${ }^{59}$ para torná-lo compatível com a cultura de alta tecnologia. ${ }^{60}$

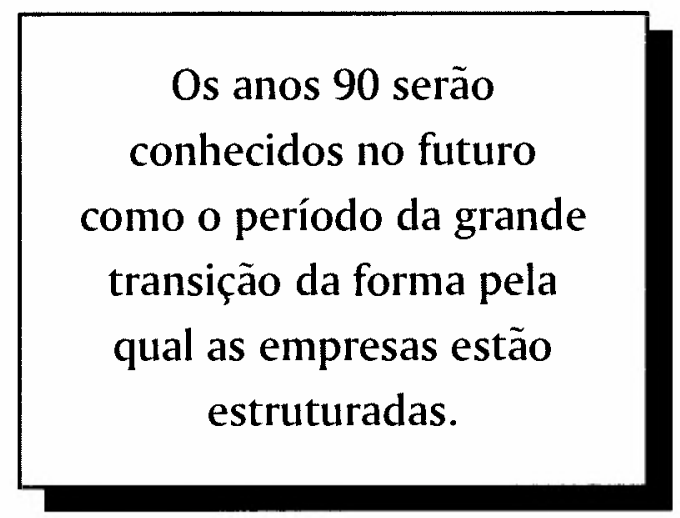

O impacto da tecnologia pode provocar transformação no trabalho das pessoas, na produção dos grupos, no desenho da própria organização e no desempenho da empresa. Uma análise rápida nos leva à conclusão de que a tecnologia tem forte ligação com os sete principais impulsionadores do novo ambiente empresarial, que são: ${ }^{61}$

- a produtividade dos "trabalhadores do conhecimento" e prestadores de serviços;

- a qualidade do produto e do serviço;

- a capacidade de resposta aos desafios de todo tipo;

- a globalização dos mercados, das operações e da concorrência;

- o outsourcing de certas atividades de produção, distribuição, vendas, serviços e funções de suporte;

- o partnering e a formação de alianças estratégicas;

- a responsabilidade social e ambiental.

A montagem e a gestão da empresa do futuro pressupõem uma profunda familiaridade do administrador com a tecnologia em todas as suas formas e variações. Acrescente-se a isso que as mudanças no trabalho,
52. MARSHALL, Edward. Transforming the way we work. New York: Amacon, 1995.

53. GALBRAITH, Jay, LAWLER III, Edward Organizando para competir no futuro. São Paulo: Makron, 1995.

54. DRUCKER, Peter. The post-capitalist society. New York: HarperCollins, 1993.

55. MILES, R., SNOW, C. Organizations new concepts for new forms, California Management Review, 1986, 28, p.62-73

56. HAMMER, Michael. $0 p$. cit

57. MORRIS, Daniel, BRANDON, Joel. Op cit.

58. GONÇALVES, José Ernesto Lima. 0 papel transformador da tecnologia. In: GONÇALVES, José Ernesto Lima Gonçalves, DREYFUSS, Cassio. Op. cit.

59. "Workplace" tem signficado mais rico do que "local de trabalho". Refere-se tanto ao posto de trabalho de cada pessoa como ao local coletivo onde o trabalho é realizado, incluindo suas dimensões sociais, ambientais e tecnológicas.

60. RIFKIN, Jeremy. Op. cit

61. TAPSCOT, Don, CASTON, Art. Op. cit 
qualquer que seja a razão, levam à necessidade de adequar a estrutura, a operação, a tripulação.

A transformação das empresas visa a atacar diretamente as mais freqüentes fontes de inércia: a aceitação das formas tradicionais de fazer negócio, a utilização da tecnologia de informação para a automação das formas antigas de trabalhar, congelando-as, a resistência em evoluir na direção de estruturas baseadas na utilização de tecnologia de informação e a certeza de que os trabalhadores não irão se demitir voluntariamente. ${ }^{62}$

A comunidade tem pressionado as empresas por causa dos empregos perdidos e as empresas se sentem acuadas. Na verdade, temos uma somatória de efeitos: por um lado o superdimensionamento da mão-de-obra resultante da utilização de padrões elásticos e adequados à época de fartura e por outro a redução da mão-de-obra necessária por causa da tecnologia. $O$ resultado é um excesso de mão-de-obra em determinadas atividades e em alguns setores que precisa ser eliminado mais cedo ou mais tarde e a empresa contemporânea deve conseguir fazer essa modificação.

Os últimos anos têm assistido o debate sobre o destino do tempo liberado pela utilização da tecnologia. Os primeiros projetos de automação de escritórios geraram uma economia de tempo da ordem de $25 \%$ da jornada das pessoas e havia a esperança de que essa economia revertesse para jornadas de trabalho mais flexíveis e ritmo de trabalho menos opressivo. Mas o que se observou foi o preenchimento do tempo liberado por outras atividades. Por outro lado, não adianta simplesmente economizar $25 \%$ do tempo de trabalho das pessoas, pois não se pode demitir $1 / 4$ de pessoa, nem mesmo vários $1 / 4$ de pessoas. $\mathrm{Na}$ verdade, é indispensável redesenhar as tarefas e redistribuir as atribuições se quisermos potencializar os benefícios da utilização da tecnologia ao nível do resultado da organização como um todo.

A tecnologia colocada à disposição das empresas permite que a concorrência possa surgir de repente, de qualquer lugar ${ }^{63}$ do mundo, de qualquer empresa, grande ou pequena, já existente ou não. Foi o caso da indústria de microcomputadores, na qual novos participantes como a Dell e a Gateway surgiram do nada para enfrentar e vencer as maiores empresas do setor. A tecnologia também está impondo uma alteração sensível no perfil e nas habilidades da mão-de-obra de todos os níveis nas empresas, ${ }^{64}$ exigindo não apenas retreinamento do pessoal, mas também sua reeducação e, eventualmente, sua substituição.

\section{O CAMINHO À FRENTE}

Essa não é a primeira nem a última mudança nas regras que interfere tão profundamente com a atividade das empresas. A transição da atividade agrícola para a atividade mercantil dos séculos XV e XVI representou um rompimento com séculos de estrita dependência com relação à atividade agrícola. $\mathrm{O}$ aperfeiçoamento da máquina a vapor no século XIX levou à transição para a atividade industrial, com o surgimento e a consolidação de setores inteiramente novos de atuação. $O$ desenvolvimento de todo um elenco de atividades produtivas baseadas no conhecimento e na informação está fazendo surgir uma nova economia, com seus novos negócios, oportunidades e riscos.

Nascido no início da Era Industrial, nosso modelo de negócio tinha características mecanicistas. Já avançamos além da Era Industrial, mas o modelo básico de negócio continua enraizado nos conceitos daquela época. ${ }^{65}$ Estamos indo além da comunicação, em direção à conectividade. As diversas partes da máquina empresarial estão aprendendo que precisam falar umas com as outras e estão procurando as maneiras de estabelecer esse diálogo.

A vantagem competitiva não acontecerá por acidente nesta nova era de negócios. As corporações devem planejar o processo de mudança, estruturar-se para conseguir implementá-lo e prosseguir na busca de posições melhores mesmo depois de terem mudado. ${ }^{66}$

O desafio para um número crescente de empresas não é identificar a mudança à qual se ajustar, mas entender que as mudanças são variadas, diversas das que já ocorreram e que frequientemente ocorrem simultaneamente. As pessoas e as organizações têm uma velocidade de mudança característica na qual elas funcionam melhor e essa velocidade é diferente de um indivíduo para outro. ${ }^{67}$ Assim, não basta reconhecer o imperativo da mu- 
dança e desejar fazê-la: é indispensável planejar a mudança da forma mais adequada.

As empresas precisarão enfrentar as conseqüências de novas preocupações e valores. Por exemplo, já que o valor do trabalho humano como "commodity" está se tornando cada vez mais tangencial e irrelevante, novas maneiras de definir o valor das relações humanas e sociais deverão ser desenvolvidas e exploradas. ${ }^{68}$

Depois de pesquisar os motivos pelos quais algumas empresas eram as grandes líderes de suas indústrias, Tom Peters passou a defender com todas as suas forças a desorganização da organização como forma de dotar a empresa das características necessárias para a sobrevivência com sucesso. ${ }^{69}$ As próprias dimensões básicas do processo de transformação do negócio mostram como a mudança deve ser profunda: o reenquadramento da direção da organização, a reestruturação da empresa, a revitalização do empreendimento e a renovação das pessoas. ${ }^{70}$ Embora propostas por Gouillart e Kelly, essas dimensões não são essencialmente diferentes daquelas sugeridas por muitos outros autores.

\section{ENFRENTANDO O DESAFIO}

As pressões por mudanças nas empresas já estão ocorrendo de forma muito clara e inten$\mathrm{sa},{ }^{71}$ mas indústrias inteiras, desde os serviços bancários até a indústria bélica, têm sido incapazes de avaliar corretamente a velocidade e o escopo dessas mudanças. ${ }^{72}$ No fundo, as empresas precisam mudar porque não estão adequadas aos novos valores (direcionamento ao cliente, qualidade). ${ }^{73}$ Por outro lado, o ciclo se fecha quando as mudanças criam necessidades não satisfeitas por tornarem obsoletos os arranjos técnicos, econômicos e organizacionais existentes, que devem, então, ser substituídos. ${ }^{74}$ A transformação do negócio é o principal desafio das diretorias e a mais importante, se não a grande, tarefa dos líderes de negócios daqui para diante. ${ }^{75}$

As novidades de todo tipo e as pressões dos negócios estão levando as empresas a desenvolverem novas competências, de maneira consciente e voluntária. $O$ domínio dessas novas competências e o preparo para explorá-las vai levar a novas estruturas organizacionais e a novas formulações de negócio. As empresas, seus diretores e seu pes- soal precisarão estar aptos a participar dessa transformação.

Se essas pressões externas e tensões internas não tivessem levado as empresas a um estado indesejável de stress e paralisia, a transformação poderia ser adiada ou até mesmo dispensada, mas, da maneira como elas ameaçam a própria existência das empresas, é necessário fazer alguma coisa eficaz e logo.

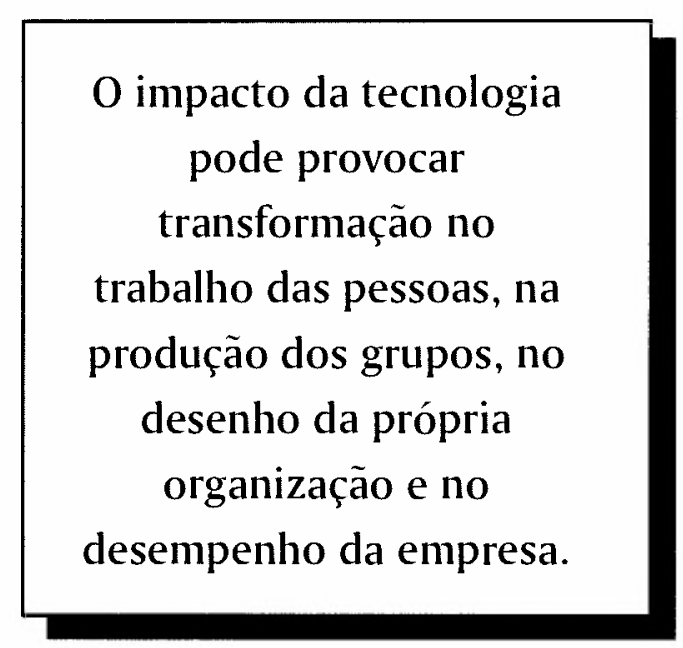

Mais importante, uma idéia está sempre presente em todos os trabalhos e na cabeça de todos os autores: as empresas podem se transformar, elas têm a possibilidade, precisam se decidir a fazê-lo, preparar-se e pôr em prática. A necessidade de se adequar continuamente às novas condições sugere que cada empresa deve construir a administração da mudança dentro si mesma. ${ }^{76}$

Um caso real, recente, é o da Xerox, que se transformou ao longo da década de 80 , conseguindo se recuperar de uma situação aparentemente insolúvel. Depois de ver sua participação no mercado de copiadoras cair de $92 \%$ para menos de $13 \%$ em 1982, a Xerox tinha planejado sair do mercado, mas decidiu enfrentar o desafio. Da qualidade do seu produto, passando pela sua forma de fazer negócio e pela própria estrutura organizacional e o estado de espírito de seu pessoal, a empresa se reformulou, num esforço exemplar.

As organizações não podem impedir o mundo de mudar. O melhor que elas podem fazer é se adaptar. As mais espertas mudam antes de serem obrigadas a fazê-lo. Aquelas de sorte conseguem dar um jeito quando a pressão inevitável chega. As outras são as perdedoras e acabam virando história. ${ }^{77} \square$
68. RIFKIN, Jeremy. Op. cit.

69. Por exemplo, ver The Tom Peters seminar. Vintage, 1994.

70. GOUILLART, Francis, KELLY, James N. Op. cit.

71. MILLS, D. Quinn. Op. cit.

72. WANT, Jerome. Op. cit.

73. WHITELEY, Richard. The customer driven company. MA: Addison-Wesley, 1991.

74. BRIDGES, William. Op. cit.

75. GOUILLART, Francis, KELLY, James N. Op. cit.

76. DRUCKER, Peter. The new society of organizations, Boston, MA: Harvard Business Review, Sep./Oct. 1992, p.95104.

77. GALUPPO, Ricardo. A destruiçãa criadora, Exame, 02 outubro 1995, p.60-62. 